\title{
A Review of Mass Masking During Covid-19 Pandemic
}

\author{
Aarathi Subodh ${ }^{1}$ and Punith Sirige ${ }^{2}$ \\ ${ }^{1}$ Medical Intern, Jawaharlal Nehru Medical College, Datta \\ Meghe Institute Of Medical Science, Sawangi, Wardha \\ ${ }^{2}$ Anaesthesiology Department ,Jawaharlal Nehru Medical College, Datta \\ Meghe Institute of Medical Science, Sawangi, Wardha \\ Corresponding author email: aarathisubodh1@gmail.com
}

\section{ABSTRACT}

In 2019, the WHO led a workshop in which they assessed the utilization of masks to deflect the effect of the flu pandemic. There was a pressing direction on the utilization of masks by everyone as a tool in fighting SARS-CoV2, the respiratory infection that causes Coronavirus. Masks have been prescribed as an expected apparatus to handle the COVID19 pandemic. The studies and experiences from flu pandemic 2009 and extreme intense respiratory condition CoV 2002-2003indicated that there is adequate motivation to utilize "mass masking" as an effective technique to tackle pandemics. Recognizing why people may be resistant to wearing masks is the first, critical step to ensure the adherence to face masking. We are influenced by the culture we live in and we fall prey to biases and misinterpretations in our decision-making. Halting a pandemic requires collective, altruistic efforts from every individual, critical thinking, risk communication, and health promotion that engages the community and addresses their concerns. This article reflects on difficulties of mass masking, effects of custom made masks and utilization of masks for control of COVID-19 pandemic.

KEY WORDS: MASKS, MASS MASKING, COVID-19, PANDEMIC, SOCIAL DISTANCING, RESPIRATORY EFFECTS.

\section{INTRODUCTION}

The end of 2019 overwhelmed the world; a novel sickness had started to fan out quickly. Few was thought about the infection, for example, course of transmission, incubatory period, or propagation number. In the end, a large number of these inquiries were discovering answers. However, numbers were taking off, and every day bore another grim tiding. Before China could seal down the influenced regions, comparable cases were springing up in different nations. Non-drug intercessions are techniques that are embraced by networks and people who are both well (to lessen introduction and stay away from contamination) and unwell (to try not to influence others) (Teasdale et al., 2014). Versatility restrictions (WHO, 2019), physical

Biosc Biotech Res Comm P-ISSN: 0974-6455 E-ISSN: 2321-4007

\section{rossef}

Identifiers and Pagination

Year: 2021 Vol: 14 No (6) Special Issue

Pages: 124-129

This is an open access article under Creative

Commons License Attribn 4.0 Intl (CC-BY).

DOI: $h t t p: / / d x$.doi.org/10.21786/bbrc/14.6.29 distancing (WHO, 2020; MOHFW, 2020; NHS, 2020) decreasing public transport (IAPT, 2020; COVID 19 internet things, 2020), and restricting social gatherings (WHO, 2020) are few of the non-drug measures attempted by the administering bodies over the globe.

In an offer to out-run the infection, the furious public purchased masks and sanitizers by the dozen subsequently compelling stores to run unavailable. This soar costs of masks even before legitimate rules from significant wellbeing associations could be delivered. It made an emergency among medical care staff, who required it the most (Gouging, 2020; Mukherjee, 2020).According to the Centers for Disease Control and Prevention (CDC) the N95 respirators, although, can be reused up to 5 times (NIOSH, 2020).

Triple-layer surgical masks, typically utilized in medical care, can channel up to 80\% of the particles (Davies et al., 2013). It is broadly concurred on that the respirators must be saved for medical services professionals (OMS, 2020; Feng et al., 2020). There are clear orders with respect to the utilization of masks by medical services experts and indicative people; in any case, till as of late, guidelines

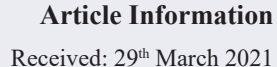
Accepted after revision: $26^{\text {th }}$ May 2021 
with respect to the utilization of masks among the overall population during the momentum pandemic was fairly ambiguous (Feng et al., 2020).Newspaper articles (Suzuki, 2020; Combating COVID-19, 2020) have guessed that, notwithstanding the group based methodology in Japan and mass screening in South Korea, a large part of the achievement in dealing with the Covid (CoV) sickness (Coronavirus) pandemic might be ascribed to the standard use of facemasks (MOHFW, 2020). Besides, they as a rule keep up distance even while welcoming one another, inadvertently rehearsing physical distancing (Norm in Japan, 2020).

Policymakers need pressing direction on the utilization of masks by everyone as a tool in fighting SARS-CoV2, the respiratory infection that causes Coronavirus. Masks have been prescribed as an expected apparatus to handle the COVID 19 pandemic since the underlying episode in China (Wang, 2019) , despite the fact that use during the flareup shifted by time and area (Feng et al., 2020) . Around the world, nations are wrestling with interpreting the proof of public cover wearing to their unique situations. These arrangements are being created in an unpredictable dynamic climate, with a novel pandemic, quick age of new examination, and outstanding development in cases and passings in numerous zones.

There is as of now a worldwide deficiency of N95 or FFP2 respirators and careful masks for use in emergency clinics. Basic fabric covers present a practical answer for use by the general population. This has been upheld by the US and European Places for Infectious prevention. We present a writing audit on the function of straightforward material masks and arrangements in decreasing Coronavirus transmission. In this article, we endeavor to answer the glaring issue at hand, "Is it viable to utilize masks in the network to moderate the Coronavirus pandemic?".

Utilization of Masks During COVID-19: "Mass making" is the use of masks by apparently sound people of the community. The World Health Organization (WHO) concurred that this methodology would assume a function in:

- Source control (forestalling the transmission of the infection by asymptomatic/pre-indicative people)

- Destigmatization of suggestive patients who wore masks.

In 2019, the WHO led a workshop in which they assessed the utilization of masks to deflect the effect of the flu pandemic. It was presumed that disregarding the absence of proof in regards to the viability of masks in lessening the movement of the pandemic "there is unthinking believability for the possible adequacy of this measure." It additionally suggested the utilization of masks out in the open during a serious pandemic (Non-Pharmaceutical, 2019). It is unquestionable that the utilization of episodic proof in controlling problematic medications, without sensible proof of adequacy presents significant logical and moral concerns (Zagury-Orly, 2020). However these worries are not comparable to careful steps like face masking. Face masking not just represents no danger to science or morals except for is, truth be told, selfless; we wear a masks to secure others, and others wear a masks to ensure us (Cheng et al., 2020). In addition, the utilization of masks is conceivably powerful and modest (Greenhalgh et al., 2020) . Mass masking in the network (in any event $70 \%$ ) utilizing high viability covers, for example, careful masks, could prompt Coronavirus end, and utilizing low adequacy masks(home-made), may in any case have some effect on the sickness trouble, contingent upon the nature of the masks (Ngonghala et al., 2020).

If wearing a mask is harmless to oneself, benefits others, and can reduce the spread of the disease, the decision should be simple. Yet the WHO and other agencies use negative messaging, that mask use will make people take risks, forget to wash their hands, or stop physical distancing. There is no evidence to support this-in fact, the evidence shows the opposite, that masks protect . Such arguments are commonly used against other public health interventions such as HPV vaccination-that vaccination will encourage promiscuity. Yet there is no evidence this is the case (Brouwer., 2019).

Recognizing why people may be resistant to wearing masks is the first, critical step to ensure the adherence to face masking. We are influenced by the culture we live in; we fall prey to biases and misinterpretations in our decision-making. Halting a pandemic requires collective, altruistic efforts from every individual, critical thinking, risk communication, and health promotion that engages the community and addresses their concerns. Concerning utilizing face covers in the network a remark was distributed in The Lancet, which expressed that, "the nonappearance of proof of viability ought not be compared to proof of ineffectiveness" (Leung et al., 2020).

Masks Among Other Strategies: Two randomized preliminaries, one by Cowling et al. (2009) and the other by Larson et al., including three interventional arms were completed as to flu pandemic of 2009. The main arm was wellbeing training, the subsequent arm was hand cleanliness, and the third was the utilization of masks and hand sanitizer. The two investigations indicated that the third arm was more powerful than the initial two. This demonstrates that utilization of face masks adds to intruding on the transmission of respiratory bead contaminations when utilized in relationship with hand cleanliness.

Difficulties of Mass Masking: Mass covering is a twofold edged blade, and simply like some other procedure, it has its cons. The June 5, 2020, interval issue by the WHO recorded a couple of issues, some of which are pointed below (Internet source, 2020):

- Particularly in infections that have more than one course of transmission, a misguided sensation that all is well and good could sneak in with the utilization 
of facemasks, prompting diminished adherence to other preventive estimates, for example, physical removing and hand cleanliness

- Ill-advised wearing and doffing practices could prompt self-pollution that can happen by contacting and reusing contaminated masks.

These issues can be tended to by conferring wellbeing training to general society. They should be shown the right techniques for wearing and doffing. It should be strengthened that the utilization of face masks is certifiably not a substitute for physical removing and hand hygiene (Cummings, 2020).

Effect of Custom made Masks: To be more ready for flare-ups of respiratory contaminations, Brienen et al. made a populace transmission model to investigate the effect of populace wide cover use. It assessed the impacts of masks viability and inclusion (i.e., number of people who use covers) on the essential multiplication number and the contamination assault pace of the flu infection. They reasoned that populace wide utilization of face masks could assume a vital function in postponing a pandemic. Masks use likewise lessens the propagation number, perhaps even to levels adequate for containing a flu outbreak (Brienen et al., 2010).

The individuals who reliably utilized the masks had a 70\% lower possibility of being determined to have SARS, while the individuals who utilized masks irregularly had a $60 \%$ lower risk. The size of the $\mathrm{CoV}$ is $0.05-0.2$ $\mu$ in diameter. Single layered natively made fabric masks(made of 100\% cotton) can channel about half of particles somewhere in the range of 0.02 and $1 \mu$ in size, while a twofold layered cover channels about 70\%.Be that as it may, material covers made of tea towels caught about $60 \%$ of particles between a similar size range (Wu et al., 2004). CDC rules suggest a "Do It Yourself" doublelayered cotton mask (Internet source, 2020b) while the WHO prescribes triple layered material mask to be utilized by the general population (OMS , 2020). The material masks need to meet the accompanying criteria (Internet sorurce, 2020b).

- It should be cozily fit

- Two layers of texture should be utilized

- The masks ought to take into simple relaxing

A gathering of researchers and specialists utilized particulate filtration to decide the insurance delivered by fabric covers for particles somewhere in the range of 0.3 and $1 \mu$ size range. 400 covers made by network volunteers were tried, and changing outcomes were gotten. They reasoned that the material picked to make the cover was crucial to its capacity to filter (Internet source, 2020c). The ideal material would be polypropylene (spunbond, and nonwoven) with a channel quality factor of $16.9 / \mathrm{kPa}$.The nature of fabric veils can be tried utilizing the flame test. In this test, a fire is held six creeps from the mouth, and the wearer endeavours to stifle the fire. On the off chance that the fire isn't extinguished, it is viewed as a "great sign".
Mask Administration: Any sort of masks, which isn't fittingly utilized and arranged, accomplishes more mischief than anything. Prior to disposing of dispensable masks alongside other waste, it is suggested that the masks are cut, to forestall reuse, and put away in a different paper pack for at any rate $72 \mathrm{~h}$. The rules while taking care of material masks are as follows (Internet source, 2020c):

- The mask should be sun-dried for about 5 h,if sundrying isn't a choice, the mask might be boiled in high temp water for 15 min with salt. Then again, a cooker might be utilized to pressure heat up the masks for $10 \mathrm{~min}$

- If nothing unless there are other options techniques is an alternative, wash with water and cleanser and apply heat on a superficial level for around $5 \mathrm{~min}$ with the help of an iron

- Hands must be washed prior to wearing the masks

- The masks must be changed when it gets soggy/ sticky

- The masks must be washed after each use

- Hand cleanliness must be rehearsed after expulsion of the masks

- Clean masks must be put away in perfect and hermetically sealed plastic covers

- Every individual necessities two facemasks, as one can be washed while the other is being utilized

- Facemasks ought not be shared between people

- Used facemasks must be put away in paper cover after use

- The last removal of masks is by consuming or profound entombment after treatment with 5\% dye or $1 \%$ sodium hypochlorite solution.

\section{CONCLUSION}

While using the masks may diminish the probability of the contamination with SARS and CoV-2, there is consistently a chance of getting the illness, especially when there is more than one course of transmission (OMS, 2020). Consequently, it is of most extreme significance that use of masks be enhanced with the other non-drug intercessions, for example, - dodging pointless contacting of the eyes, nose, and mouth, hand cleanliness, cough etiquette, physical distancing, abstain from parties, and quarantine and isolate. Mass creation is a normal illustration of the "prevention paradox," where it offers some advantage to the individual and loads helpful for the community, especially in settings where physical distance acts like a challenge (Internet source, 2020c).

The advantages of mass concealing a network outgauge the dangers. In the event that triple-layered material masks are received for public use, there will be a satisfactory inventory of triple employ careful covers and N95 respirators for bleeding edge laborers who are in critical need. Transmission from individuals with asymptomatic disease has been very much archived, in spite of the fact that it is hazy how much such 
transmission adds to the general spread of infection (Rothe et al., 2020).

More guileful might be the medical services specialist who comes to work with gentle and equivocal manifestations, for example, weakness or muscle throbs, or a scratchy throat and nasal clog, that they property to working extended periods or stress or occasional hypersensitivities, instead of perceiving that they may have early or mild Coronavirus. In our emergency clinics, we have just observed various occasions in which staff individuals either came to function admirably yet created manifestations of Coronavirus partially through their works day or worked with mild and vague indications that were along these lines analyzed as Coronavirus. These cases have prompted huge quantities of our patients and staff individuals being presented to the infection and a modest bunch of possibly connected contaminations in medical care laborers. Concealing everything suppliers may restrict transmission from these sources by halting asymptomatic and insignificantly suggestive medical care laborers from spreading infection loaded oral and nasal beads.

What is clear, nonetheless, is that general covering alone isn't a panacea. A mask won't secure suppliers thinking about a patient with dynamic Coronavirus if it's not joined by careful hand cleanliness, eye assurance, gloves, and an outfit. A mask alone won't forestall medical services laborers with early Coronavirus from defiling their hands and spreading the infection to patients and associates. Focusing in on all-inclusive masking alone may, amazingly, lead to more transmission of Coronavirus in the event that it redirects consideration from executing more major disease control measures.

Such measures incorporate overwhelming screening of all patients going to an office for side effects of Coronavirus and promptly getting them covered and into a room; early usage of contact and bead safeguards, including eye assurance, for every single suggestive patient and deciding in favor of alert if all else fails; rescreening all conceded patients day by day for signs and indications of Coronavirus in the event that a disease was brooding on confirmation or they were presented to the infection in the medical clinic; having a low limit for testing patients with even gentle manifestations possibly inferable from a viral respiratory contamination (this incorporates patients with pneumonia, given that a third or a greater amount of pneumonias are brought about by infections instead of microbes); expecting representatives to authenticate that they have no manifestations prior to beginning work every day; being mindful to physical distancing between staff individuals in all settings (counting conceivably ignored settings, for example, lifts, clinic rounds, and work rooms); confining and screening guests; and expanding the recurrence and unwavering quality of hand cleanliness.

The degree of negligible advantage of widespread covering far beyond these central measures is disputable. It relies upon the commonness of medical services laborers with asymptomatic and insignificantly indicative diseases just as the general commitment of this populace to the spread of contamination. It is educational, in such manner, that the predominance of Coronavirus among asymptomatic evacuees from Wuhan during the stature of the pestilence there was simply 1 to $3 \%$ (Hoehl et al., 2019). Modelers evaluating the spread of disease in Wuhan have noticed the significance of undiscovered contaminations in filling the spread of Coronavirus while likewise recognizing that the transmission hazard from this populace is probably going to be lower than the danger of spread from suggestive patients (Li et al., 2020). And afterward the expected advantages of widespread covering should be adjusted against the future danger of running out of veils and subsequently presenting clinicians to the a lot more serious danger of thinking about indicative patients without a cover.

Furnishing every medical care specialist with one cover for each day for broadened use, notwithstanding, may oddly improve stock control by lessening one-time utilizes and encouraging concentrated work processes for assigning covers without hazard appraisals at the individual-representative level (Khatib et al., 2020). A number of related articles reflected on this issue (Gaidhane et al., 2020; Jachak et al., 2020; Joseph et al., 2020; Joshi et al., 2020; Lakhkar et al., 2020). It is likewise evident that masks serve representative jobs. Masks are not just tools, they are additionally charms that may help increment medical care laborers' apparent feeling of wellbeing, prosperity, and trust in their emergency clinics (Sharma et al, 2020; Somashekhar et al., 2020; Taksande et al., 2020; Kolhe et al., 2020).

Moreover such responses may not be carefully consistent, we are altogether liable to dread and uneasiness, particularly during the time of emergency (Acharya et al., 2020). One may contend that dread and tension are better countered with information and training than with a possibly advantageous masks, especially considering the overall mask deficiency, however it is hard to get clinicians to hear this message in the warmth of the current emergency. Extended masking conventions' most noteworthy commitment might be to decrease the transmission of uneasiness, well beyond whatever job they may play in lessening transmission of Coronavirus. The possible estimation of widespread covering in giving medical care laborers the certainty to retain and execute the more fundamental contamination anticipation rehearses portrayed above might be its most prominent commitment.

\section{REFERENCES}

Acharya, S., Shukla, S. and Acharya, N., 2020. Gospels of a pandemic-A metaphysical commentary on the current COVID-19 crisis.

Advice on the Use of Masks in the Contex of COVID19. 2020a. Available from: https://www.who.int/ publications [Last accessed on 2020 Apr 25].

Advisory on use of Homemade Protective Cover for Face and Mouth; 2020d. Available from:https://www. 
mohfw.gov.in/ pdf/AdvisoryctManualonuseofHomema deProtectiveCoverfor FaceEtMouth.pdf. [Last accessed on 2020 Apr 26].

Amazon Hand Sanitizer: Report Finds COVID-19 Price Spikes, Gouging; 2020.

Bai, Y., Yao, L., Wei, T., Tian, F., Jin, D.Y., Chen, L. and Wang, M., 2020. Presumed asymptomatic carrier transmission of COVID-19. Jama, 323(14), pp.14061407.

Brienen, N.C., Timen, A., Wallinga, J., Van Steenbergen, J.E. and Teunis, P.F., 2010. The effect of mask use on the spread of influenza during a pandemic. Risk Analysis: An International Journal, 30(8), pp.1210-1218.

Brouwer, A.F., Delinger, R.L., Eisenberg, M.C., Campredon, L.P., Walline, H.M., Carey, T.E. and Meza, R., 2019. HPV vaccination has not increased sexual activity or accelerated sexual debut in a college-aged cohort of men and women. BMC Public Health, 19(1), pp.1-8.

Centers for Disease Control and Prevention. Recommended Guidance for Extended Use and Limited Reuse of N95 FilteringFace piece Respirators in Healthcare Settings NIOSH Workplace Safety and Health Topic. Available from: https://www.cdc.gov/ iosh/topics/hcwcontrols/ recommendedguidanceextuse.html.[Last accessed on 2020 Apr 26]

Centers for Disease Control and Prevention. Use Cloth Face Coverings to Help Slow Spread. Atlanta, Georgia, United States: Centers for Disease Control and Prevention. 2020b. Available from: https://www. cdc.gov/coronavirus/2019-ncov/preventgetting-sick/ diy-cloth-face-coverings.html. [Last accessed on 2020 Apr 25].

Cheng, K.K., Lam, T.H. and Leung, C.C., 2020. Wearing face masks in the community during the COVID-19 pandemic: altruism and solidarity. The Lancet.

Combating COVID-19: Lessons from South Korea. Available from: https://www.brookings.edu/blog/ techtank/2020/04/13/ combating-covid-19-lessonsfrom-south-korea. [Last accessed on 2020 Apr 26]. Corona virus (COVID-19): Physical Distancing|NHS Inform. Available from: https://www.nhsinform.scot/ illnesses-andconditions/infections-and-poisoning/ coronavirus-covid-19/ coronavirus-covid-19-physicaldistancing. [Last accessed on 2020 Apr 26].

Corona virus and Your Commute: How COVID19 is Affecting Public Transportation around the World:Moovit. Available from: http://www. company.moovit.com/blog/coronavirus-effect-publictransportation-worldwide. [Last accessed on $2020 \mathrm{Apr}$ 26].

Cowling, B.J., Chan, K.H., Fang, V.J., Cheng, C.K., Fung, R.O., Wai, W., Sin, J., Seto, W.H., Yung, R., Chu, D.W. and Chiu, B.C., 2009. Facemasks and hand hygiene to prevent influenza transmission in households: a cluster randomized trial. Annals of internal medicine, 151(7), pp.437-446.
Cummings, M., 2020. Edmontonians Embracing Nonmedical Masks, CBC News. CBC News.

Davies, A., Thompson, K.A., Giri, K., Kafatos, G., Walker, J. and Bennett, A., 2013. Testing the efficacy of homemade masks: would they protect in an influenza pandemic?. Disaster medicine and public health preparedness, 7(4), pp.413-418.

Feng, S., Shen, C., Xia, N., Song, W., Fan, M. and Cowling, B.J., 2020. Rational use of face masks in the COVID-19 pandemic. The Lancet Respiratory Medicine, 8(5), pp.434-436.

Feng, S., Shen, C., Xia, N., Song, W., Fan, M. and Cowling, B.J., 2020. Rational use of face masks in the COVID-19 pandemic. The Lancet Respiratory Medicine, 8(5), pp.434-436.

Gaidhane, S., Khatib, N., Zahiruddin, Q.S., Gaidhane, A., Telrandhe, S. and Godhiwal, P., 2020. Depression, anxiety and stress among the general population in the time of COVID-19 lockdown: A cross-sectional study protocol. International Journal of Research in Pharmaceutical Sciences, 11(Special Issue 1).

Greenhalgh, T., Schmid, M.B., Czypionka, T., Bassler, D. and Gruer, L., 2020. Face masks for the public during the covid-19 crisis. Bmj, 369.

Hoehl, S., Rabenau, H., Berger, A., Kortenbusch, M., Cinatl, J., Bojkova, D., Behrens, P., Böddinghaus, B., Götsch, U., Naujoks, F. and Neumann, P., 2020. Evidence of SARS-CoV-2 infection in returning travelers from Wuhan, China. New England Journal of Medicine, 382(13), pp.1278-1280.

International Association of Public Transport. Management of COVID-19 Guidelines for Public Transport Operators; 2020. Available from: https:// www.uitp.org/sites/default/files/cckfocus-papers-files/ Corona Virus_EN.pdf. [Last accessed on 2020 Apr 26]. Joseph, M.B., Pohekar, S., Raut, A. and Patil, M., 2020. The palliative care and covid-19 pandemic. International Journal of Research in Pharmaceutical Sciences, 11(Special Issue 1).

Khatib, M.N., Gaidhane, S., Khatib, M., Ahmed, M., Gaidhane, A. and Syed, Z.Q., 2020. SARS-CoV and SARS-CoV-2: Similar viruses with different trajectories. Wutan Huatan Jisuan Jishu, 16(5).

Kolhe, Seema, MinalDambhare, Priya Dhankasar, Pallavi Dhole, Ashwathy Nair, and Priya Rewatkar. 2020. Home Remedies During Covid Pandemic Lockdown. Journal Of Research In Medical And Dental Science, 8(6),pp.103-7.

Lakhkar, B.B., Guru, S., Damke 2020. Most Susceptible Duo in COVID-19 Crisis: A Literature Review. Perinatology ,21(3),pp.112-23.

Larson, E.L., Ferng, Y.H., Wong-McLoughlin, J., Wang, S., Haber, M. and Morse, S.S., 2010. Impact of nonpharmaceutical interventions on URIs and influenza in crowded, urban households. Public health reports, 125(2), pp.178-191.

Latchoumi, T.P., Ezhilarasi, T.P. and Balamurugan, K., 
2019. Bio-inspired weighed quantum particle swarm optimization and smooth support vector machine ensembles for identification of abnormalities in medical data. SN Applied Sciences, 1(10), pp.1-10.

Leung, C.C., Lam, T.H. and Cheng, K.K., 2020. Mass masking in the COVID-19 epidemic: people need guidance. Lancet, 395(10228), p.945.

Li, R., Pei, S., Chen, B., Song, Y., Zhang, T., Yang, W. and Shaman, J., 2020. Substantial undocumented infection facilitates the rapid dissemination of novel coronavirus (SARS-CoV-2). Science, 368(6490), pp.489-493.

Ministry of Health and Family Welfare, Government of India. Advisory on Social Distancing Measure in View of Spread of COVID-19 Disease. Available from: https://www. mohfw. gov.in/pdf/SocialDistancingAdvisorybyMOHFW. pdf.[Last accessed on 2020 Apr 26].

Mukherjee, R.B., 2020. Coronavirus Mask Shortage Coronavirus Terror in India: Sanitisers. Masks Sold Out, Prices Peak.

Ngonghala, C.N., Iboi, E., Eikenberry, S., Scotch, M., MacIntyre, C.R., Bonds, M.H. and Gumel, A.B., 2020. Mathematical assessment of the impact of nonpharmaceutical interventions on curtailing the 2019 novel Coronavirus. Mathematical biosciences, 325, p.108364.

Nisargandha, M.A. and DadaraoParwe, S., 2020. Spread of coronavirus disease 2019 (COVID-19) during the lockdown in the Indian population and preventive measures. International Journal of Research in Pharmaceutical Sciences, 11, pp.328-332.

Report of the WHO-China Joint Mission on Corona virus Disease; 2019. Available from: https://www.who. int/docs/ default-source/coronaviruse/who-china-jointmission-oncovid-19-final-report.pdf.[Last accessed on 2020 Apr 26]

Rothe, C., Schunk, M., Sothmann, P., Bretzel, G., Froeschl, G., Wallrauch, C., Zimmer, T., Thiel, V., Janke, C., Guggemos, W. and Seilmaier, M., 2020. Transmission of 2019-nCoV infection from an asymptomatic contact in Germany. New England journal of medicine, 382(10), pp.970-971.

Rudhrabatla, V.S.A., Sudhakar, B. and Reddy, K.V.N., 2019. Ritonavir loaded surface modified stealth solid lipid nanoparticles: full factorial design and pharmacokinetic studies. Int. J. Res. Pharm. Sci, 10, pp.77-89.

Sharma, R.P., Pohekar, S.B. and Ankar, R.S., 2020. Role of a Nurse in COVID-19 Pandemic. Journal of Evolution of Medical and Dental Sciences, 9(35), pp.2550-2556.

Social Distancing is the Norm in Japan. That's why COVID19 Spread is Slow There. Available from: https:// www.theprint. in/health/social-distancing-is-thenorm-in-japan-thats-whycovid-19-spread-is-slowthere/384498. [Last accessed on 2020 Apr 26].

Somashekhar, S.P., Shivaram, H.V., Abhaham, S.J., Dalvi, A., Kumar, A., Gode, D., Misra, S., Jain, S.K., Prasad, C.R.K. and Pillarisetti, R.R., 2020. ASI's consensus guidelines: $\mathrm{ABC}$ s of what to do and what not during the COVID-19 pandemic.

Suzuki, K., 2020. COVID-19 strategy: the Japan model. The Japan Times, 28.

Taksande, Amar, Abhilasha Singh R. Panwar, Syed AthharSaqqaf, Rupesh Rao, and RevatMeshram. 2020. Study of Knowledge, Attitude and Practice (KAP) towards COVID-19 Pandemic in Rural Area. MEDICAL SCIENCE 24(106), pp.4144-57.

Teasdale, E., Santer, M., Geraghty, A.W., Little, P. and Yardley, L., 2014. Public perceptions of nonpharmaceutical interventions for reducing transmission of respiratory infection: systematic review and synthesis of qualitative studies. BMC public health, 14(1), pp.117.

Testing Shows Type of Cloth Used in Homemade Masks Makes a Difference, Doctors Say Wake Forest Baptist Medical Center. News Release; 2020c. Available from: https://www. newsroom.wakehealth.edu/NewsReleases/2020/04/TestingShows-Type-of-Cloth-Usedin-Homemade-Masks-Makes-aDifference. [Last accessed on 2020 Apr 26].

Use of Cloth Face Mask to Help Slow the Spread of COVID19 Advisory on Use of Face Mask. 2020e. Availablefrom:https:// www.health.odisha.gov.in/pdf/ Use-of-Cloth-Face-Mask-toHelp-Slow-the-Spread-ofCOVID-19.pdf. [Last accessed on 2020 Apr 26].

Wang, C. Yu. 2019. Letter to editor: Role of masks/ respirator protection against 2019-novel coronavirus (COVID-19).

WHO/Europe/WHO Expert Mission to Belarus Recommends Physical Distancing Measures as COVID19 Virus Transmits in the Community. Available from: http://www.euro.who.int/ en/countries/belarus/ news/news/2020/4/who-expert-missionto-belarusrecommends-physical-distancing-measures-ascovid19-virus-transmits-in-the-community. [Last accessed on 2020 Apr 26].

World Health Organization, 2019. Non-pharmaceutical public health measures for mitigating the risk and impact of epidemic and pandemic influenza: annex: report of systematic literature reviews (No. WHO/WHE/ IHM/GIP/2019.1). World Health Organization.

World Health Organization, 2020. Advice on the use of masks in the context of COVID-19: interim guidance, 6 April 2020 (No. WHO/2019-nCov/IPC_Masks/2020.3). World Health Organization.

Wu, J., Xu, F., Zhou, W., Feikin, D.R., Lin, C.Y., He, X., Zhu, Z., Liang, W., Chin, D.P. and Schuchat, A., 2004. Risk factors for SARS among persons without known contact with SARS patients, Beijing, China. Emerging infectious diseases, 10(2), p.210.

Zagury-Orly, I. and Schwartzstein, R.M., Covid-19-a reminder to reason [published online ahead of print April 28, 2020]. N Engl J Med. https://doi. org/10.1056/ NEJMp2009405. 